\title{
Sazonalidade na comunidade de Coleoptera em duas fitofisionomias de Caatinga
}

\author{
Seasonality in the Coleoptera community in two Caatinga phytophysiognomies
}

\author{
Rozileudo da Silva Guedes ${ }^{\mathrm{I}}$, Fernando César Vieira Zanella" \\ Paschoal Coelho Grossi ${ }^{\text {III }}$
}

\begin{abstract}
Resumo
Variações temporais nas condições climáticas e nos recursos tróficos têm forte influência sobre a abundância de insetos em ambientes xerófilos de Caatinga, sendo essa região semiárida tropical caracterizada por uma longa estação seca e uma chuvosa. Duas áreas características dessa região foram monitoradas quanto à variação sazonal na fauna de coleópteros, próximo a uma mata ciliar sempre verde e em vegetação xerófila caducifólia no Semiárido da Paraíba, determinados pelos distintos períodos de chuvas e de seca. Diante disso, investigou-se a variação sazonal de coleópteros próximo a uma mata ciliar em relação a uma área de vegetação xerófila em região de Caatinga no Semiárido da Paraíba. O objetivo deste estudo foi comparar a variação sazonal na abundância, composição e riqueza de espécies nessas duas fitofisionomias e, avaliando possíveis evidências de que ambientes mésicos sirvam como refúgio para ao menos parte das espécies durante o período seco. Amostras semanais com armadilha Malaise foram obtidas ininterruptamente durante quatro anos em cada área. Foi registrada uma forte variação sazonal na comunidade de besouros na vegetação xerófila, sendo encontradas diferenças entre os períodos chuvoso e seco no número médio de espécies e de indivíduos por amostra, mas mais próximo da mata ciliar não foram registradas diferenças significativas. A substituição de espécies entre amostras foi o componente que mais contribuiu para a diversidade beta em ambas as fitofisionomias. Os resultados encontrados quanto à variação na riqueza e abundância das espécies entre as estações seca e chuvosa corroboram evidências prévias do caráter fortemente sazonal da comunidade de besouros em vegetação xerófila na Caatinga, mas a ausência de variação significativa próximo à mata ciliar é interpretada como indicativo da importância de áreas mésicas como refúgio durante a estação seca nesta região semiárida, ao menos para algumas espécies. Devendo ser estudado cada grupo de espécies para confirmar o papel dessas áreas na dinâmica populacional e na manutenção de indivíduos adultos ativos durante o período seco.
\end{abstract}

Palavras-chave: Floresta tropical seca; Ambientes mésicos; Riqueza de espécies; Abundância

\footnotetext{
Engenheiro Florestal, Dr., Professor da Unidade Acadêmica de Engenharia Florestal, Universidade Federal de Campina Grande, Av. Universitária, s/n, Santa Cecília, CEP 58708-110, Patos (PB), Brasil. rozileudo@gmail.com (ORCID: 0000-0002-8556-0183)

II Biólogo, Dr., Professor do Programa de Pós-Graduação em Biodiversidade Neotropical, Universidade Federal da Integração Latino-Americana, Av. Tarquinio Joslin dos Santos, 1000, Jardim Universitário, CEP 85867-000, Foz do Iguaçu (PR), Brasil. fcvzanella@gmail.com (ORCID: 0000-00018466-8988)

III Engenheiro Agrônomo, Dr., Professor do Departamento de Agronomia, Universidade Federal Rural de Pernambuco, Rua Manuel Medeiros, s/n, Dois Irmãos, CEP 52171-900, Recife (PE), Brasil. paschoal.grossi@gmail.com (ORCID: 0000-0001-6601-5967)
} 


\begin{abstract}
Temporal variations in climatic conditions and trophic resources have strong influence on the abundance of insects in the xerophilous environments of Caatinga, being this tropical semiarid region characterized as having a long dry season and also a long rainy one. Two characteristic habitats in this region were investigated regarding the seasonal variation in the beetle's fauna, near an evergreen riparian forest and at a deciduous xerophytic vegetation in Paraíba state, in northeastern Brazil. The aim of this study was to compare the seasonal variation in abundance, composition and richness of Coleoptera species in these two phytophysiognomies, evaluating possible evidences that mesic habitats serve, at least for some species, as refuges during the dry seasons. Weekly samples with malaise trap were carried out uninterruptedly in each area, during four years. There was a strong seasonal variation in the community of beetles in the xerophilous vegetation, with differences in the average number of individuals and species between rainy and dry season samples. However, no significant differences were recorded near the riparian forest. The species turnover was the component that contributed the most to beta diversity in both phytophysiognomies. The results regarding variation in richness and abundance of the species between dry and rainy seasons corroborate the previous evidences of the strong seasonality of the community of beetles in the Caatinga xerophilous vegetation, but the absence of such variation in the riparian forest is interpreted as an indicative of the importance of the mesic habitats as refuges during the dry season, at least for some species. Each species group must be studied in order to confirm the role of these areas in the population dynamics and in the permanence of active adult individuals during dry season.
\end{abstract}

Keywords: Dry tropical forest; Mesic environments; Species richness; Abundance

\title{
Introdução
}

A abundância de insetos em ecossistemas tropicais secos pode variar ao longo do ano por várias razões, incluindo mudanças macro e microclimáticas, e variação na disponibilidade de recursos vegetais (WOLDA, 1988; PINHEIRO et al., 2002) que, no caso dos insetos herbívoros, são as próprias plantas hospedeiras.

As condições meteorológicas da região da Caatinga, como alta radiação solar, temperatura anual elevada relativamente estável, precipitações relativamente baixas e irregulares ao longo do ano, definem para a região um clima fortemente sazonal, com duas estações bem definidas: a chuvosa e a seca (SILVA et al., 2017a). A sazonalidade é determinada pelo curto e irregular período de chuvas, o que define as fenofases da vegetação. Usualmente a maioria dos eventos de chuvas se concentra em três meses consecutivos (50-70\%), apesar de haver grande variação anual. É característico um longo período de estiagem, podendo ser de sete a onze meses, dependendo da localidade, no qual a vegetação xerófila perde quase que totalmente a folhagem, com exceção de poucas espécies perenifólias (PRADO, 2003).

A precipitação é apontada como o principal fator climático que governa a dinâmica das comunidades de insetos nos ecossistemas tropicais (PINHEIRO et al., 2002; VASCONCELLOS et al., 2010). A Caatinga é o bioma mais representativo do Nordeste do Brasil, sendo formado predominantemente por florestas tropicais secas (PENNINGTON et al., 2004). Nas áreas em que a escassez de água é mais severa ocorre uma diminuição na diversidade de besouros no período seco, chegando a não serem observados adultos ativos de alguns táxons, aparecendo novamente após o início do período chuvoso (HERNÁNDEZ, 2007). O declínio na abundância durante o período seco foi observado para várias ordens de insetos em vegetação xerófila na Caatinga, incluindo Coleoptera (ZANELLA, 2003; VASCONCELLOS et al., 2010; ANSELMO et al., 2014),mas, as estratégias de cada espécie ou grupo para sobreviver nesta região semiárida tropical, especialmente a forma como atravessam a estação seca é uma questão importante de investigação.

Para atravessar o período adverso os insetos podem apresentar basicamente duas estratégias: migrar no espaço, deslocando-se para áreas que apresentem recursos necessários à sobrevivência ou migrar no tempo, por meio de processos de dormência (diapausa ou quiescência). Nesse sentido, as florestas ciliares, bem como plantas sempre verdes (perenifólias) (SILVA; NEVES, 2014) e áreas com culturas irrigadas ou próximo de açudes são ambientes que podem atuar como refúgios para 
insetos durante períodos secos do ano em regiões tropicais secas, não sendo necessário atravessar o período seco como inativo. Não foi encontrado na literatura nenhum trabalho analisando a variação temporal na estrutura da comunidade de besouros em ambiente de mata ciliar no bioma Caatinga e, considerando a limitação em se obter dados de biologia para todas as espécies que ocorrem na região, uma forma de se avaliar o papel de uma área mésica para um grupo diversificado, como Coleoptera, é comparar a variação na abundância e diversidade de espécies em áreas próximas, uma mésica e outra com vegetação xerófila concomitantemente, estando sujeitas, portanto, ao mesmo regime climático (ZANELLA, 2003).

A ordem Coleoptera é detentora da maior riqueza taxonômica conhecida de organismos (BOUCHARD et al., 2017), sendo encontrada em todos os ambientes terrestres e com os mais diferenciados hábitos e níveis tróficos (CASARI; IDE, 2012). Os grupos de espécies apresentam diferentes regimes alimentares, apenas não incluindo a hematofagia (CASARI; IDE, 2012) e desempenham papéis fundamentais nos ecossistemas, incluindo deterioração da matéria orgânica, herbivoria e controle de pragas (CASARI; IDE, 2012; GULLAN; CRANSTON, 2012). Nesse sentido, é importante investigar como ocorre a variação sazonal nas comunidades de Coleoptera considerando os diferentes ambientes que ocorrem na Caatinga, levando-se em conta a diversidade de biologias e de papéis ecológicos.

Sendo assim, este trabalho teve por objetivo comparar a variação sazonal na abundância, composição e riqueza de espécies de Coleoptera em duas áreas próximas com diferentes fitofisionomias, uma de vegetação xerófila e outra próxima à mata ciliar, na região semiárida do estado da Paraíba, avaliando a presença de evidências que corroborem a hipótese de que a área mésica serve como refúgio para ao menos parte da fauna de Coleoptera durante o período seco. Assume-se que a área próxima à mata ciliar apresenta melhores condições para a manutenção de adultos ativos durante o período seco, devido à maior disponibilidade e diversidade de recursos alimentares, além de condições microclimáticas com menor estresse hídrico, o que fornece condições mais favoráveis à comunidade de besouros em comparação à área com a vegetação xerófila de Caatinga.

\section{Material e métodos}

\section{Caracterização da área de estudo, amostragem da ordem Coleoptera e identificação dos táxons}

A amostragem foi realizada na Fazenda Tamanduá $\left(37^{\circ} 24^{\prime} 22,5^{\prime \prime} \mathrm{O} ; 07^{\circ} 01^{\prime} 30,3^{\prime \prime S}\right)$, município de Santa Terezinha, Paraíba. As temperaturas médias anuais na região variam pouco, entre 26 a $28^{\circ} \mathrm{C}$, e a precipitação média usualmente entre 500 a 800 mm anuais na Depressão Sertaneja Setentrional, na qual se encontra a área de estudo, com elevado deficit hídrico e dois períodos pluviométricos distintos: o chuvoso e o seco (segundo semestre do ano, podendo ser mais longo) (VELLOSO; SAMPAIO; PAREYN, 2002), no entanto, há grande variação entre os anos. No período de amostragem, a precipitação anual variou entre 435,6 a 1537,9 mm (dados da Estação Pluviométrica da Fazenda Tamanduá).

Foram obtidas amostras semanais em duas áreas próximas, mas com fitofisionomias diferentes, uma de vegetação xerófila decídua típica de Caatinga e outra próxima a remanescentes mata ciliar sempre verde, com a utilização simultânea e ininterrupta de armadilha do tipo malaise sendo uma em cada área, de novembro de 2009 a outubro de 2013. A área de vegetação xerófila encontra-se preservada há cerca de 30 anos, com baixa interferência antrópica, totalizando 325 ha. Na área mésica, a armadilha foi colocada em área aberta, vizinha à estreita faixa de remanescente de floresta. Em cada fitofisionomia amostrada a armadilha revezava entre três pontos amostrais a cada quatro semanas. No momento de troca amostral foi realizada a troca de armadilha entre as áreas, a fim de evitar a influência da eficiência diferencial na amostragem devido a eventuais características diferentes de cada equipamento de coleta. A malaise é uma tenda de náilon e fica suspensa por hastes de ferro, com 
dimensões de 1,70 $\mathrm{m}$ de comprimento, $1,50 \mathrm{~m}$ de altura na parte da frente e $0,90 \mathrm{~m}$ na parte posterior. O tecido superior era de cor branca e o inferior, de interceptação de voo, era de cor transparente. O frasco coletor foi disposto voltado para o Norte e a malaise com orientação no sentido Sul-Norte. O frasco coletor era um recipiente plástico adaptado, preenchido com álcool etílico hidratado 92,8 INPM, para conservar os insetos coletados. Esse tipo de armadilha intercepta os insetos durante o voo, não utilizando, assim, atrativo. Foram triados com auxílio de microscópio estereoscópico e reconhecidos inicialmente em termos de família utilizando bibliografia especializada. Contou-se com a colaboração de especialistas para a identificação em níveis hierárquicos inferiores (GUEDES; ZANELLA; GROSSI, 2019). Os exemplares amostrados semanalmente foram acondicionados em álcool 70\%, triados, montados em alfinetes entomológicos, secos e etiquetados. Voucher foram depositados nas coleções dos laboratórios de Taxonomia de Insetos da Universidade Federal Rural de Pernambuco, campus de Recife (CERPE), Pernambuco, e de Entomologia Florestal da Universidade Federal de Campina Grande (UFCG), campus de Patos, Paraíba.

\section{Análise dos dados}

Para caracterização da comunidade de Coleoptera amostrada foram analisadas a riqueza de espécies e a abundância de indivíduos por estação, e calculado o índice de diversidade de Shannon $\left(H^{\prime}\right)$ (MAGURRAN,2011).

$\mathrm{Na}$ análise dos períodos chuvoso e seco excluíram-se os meses que são de transição entre os períodos (início e fim de cada estação) e foram comparados apenas os meses do quadrimestre tipicamente chuvoso (fevereiro - maio) e o seco (agosto - novembro) de cada ano, para que se pudesse ter um contraste mais evidente com o período de maior estresse hídrico do ano na região, minimizando em parte o problema de se agruparem dados de anos diferentes climatologicamente, especialmente quando a estação chuvosa se estendeu mais do que quatro meses e aqueles que ela estava concentrada em menos de quatro meses.

Para avaliar a similaridade entre os períodos do ano para cada área foram utilizados os índices de Jaccard (que considera apenas composição) e o índice de diversidade beta $(\beta)$ de Whitaker (MAGURRAN, 2011), que representa a diversidade de diferenciação entre as áreas na comparação entre os períodos do ano.

Para estimar a riqueza de espécies da fauna de Coleoptera para os períodos chuvoso e seco em cada fitofisionomia estudada, utilizou-se o estimador Chao1 por meio da Equação (1):

$S_{\text {est }}=S_{\text {obs }}+\left(a^{2} / 2 b\right)$

onde: $S=$ número de espécies, estimado $\left(S_{\text {ess }}\right)$ e observado $\left(S_{o b s}\right) ; a=$ número de espécies com apenas um indivíduo e $b=$ número de espécies com dois indivíduos. Foram utilizados os termos singleton para as espécies com um único indivíduo e doubleton para as espécies com apenas dois indivíduos, de acordo com Colwell (2005).

Os dados de riqueza de espécies e abundância de indivíduos foram submetidos ao teste de normalidade de Shapiro-Wilk e, quando necessário, os dados foram logaritimizados visando obter a distribuição normal. Em seguida, a riqueza e a abundância média dos Coleoptera foram comparadas por meio da realização do teste $t$, a fim de averiguar diferenças existentes entre os períodos chuvoso e seco em cada ambiente estudado com relação a esses parâmetros.

Para verificar o efeito das variáveis climáticas na variação da abundância de besouros ao longo do ano, utilizou-se o coeficiente de correlação de Spearman para as seguintes variáveis: precipitação acumulada, temperatura média e umidade relativa do ar média, sendo utilizados dados semanais para todas as análises. Os dados meteorológicos referentes à temperatura e umidade relativa do ar foram obtidos da estação automática da Universidade Federal de Campina Grande (UFCG) para a cidade de Patos, $\mathrm{PB}$, que fica localizada a aproximadamente $15 \mathrm{~km}$ do local de amostragem e possui a mesma altitude. Já, os dados referentes à precipitação, durante o período amostral, foram obtidos 
a partir de uma miniestação instalada na própria Fazenda Tamanduá.

Para testar quais componentes da diversidade beta (substituição de espécies ou aninhamento) contribuem mais como mecanismo do padrão na composição das espécies dentro de cada área, foi utilizada a decomposição da diversidade beta em seus componentes como proposto por Baselga (2010).

Diferenças estatísticas na composição das espécies da fauna de Coleoptera e entre os períodos chuvoso e seco do ano para as duas fitofisionomias estudadas foram medidas por meio da análise de variância multivariada permutacional (PERMANOVA) (ANDERSON, 2001), por comparações múltiplas, utilizando a função "adonis", seguida de Análise de Coordenadas Principais (PCoA), para se averiguarem as diferenças na composição de espécies entre as áreas.

Todas as análises foram realizadas utilizando o programa $R$ ( $R$ DEVELOPMENT CORE TEAM,2016). Para as análises de diversidade, de estimativa de espécies e de suficiência amostral utilizou-se o pacote vegan (OKSANEN et al., 2013), para a decomposição da diversidade beta foi usado o pacote betapart (BASELGA; ORME, 2012), enquanto para as análises de PERMANOVA e PCoA foi utilizado o pacote ade4 (DRAY et al., 2018).

\section{Resultados e discussão}

Foram amostradas 42 famílias de Coleoptera distribuídas em 383 espécies e um total de 6.567 indivíduos. Sendo coletadas próximo à mata ciliar 39 famílias, 329 espécies e 4.412 indivíduos, e 34 famílias, 214 espécies e 2.155 indivíduos na área de vegetação xerófila (a relação de espécies é apresentada em GUEDES; ZANELLA; GROSSI, 2019). Comparando-se o número de famílias nos períodos seco e chuvoso nos dois ambientes em relação ao número total, o maior percentual foi durante o período chuvoso próximo à mata ciliar $(87 \%)$ e o menor no período seco na vegetação xerófila (53\%). Das 39 famílias registradas para a mata ciliar, 28 foram comuns aos dois períodos do ano, seis foram exclusivas do quadrimestre chuvoso, compreendendo 85 indivíduos, a maioria de Lampyridae, e quatro espécies foram coletadas apenas durante o quadrimestre seco, para 24 indivíduos, a maioria de Throscidae. Para a vegetação xerófila, do total de famílias amostradas (34), 17 foram comuns nas duas estações do ano. No entanto, 11 tiveram ocorrência restrita ao quadrimestre de chuvas, compreendendo 109 indivíduos, e apenas uma, representada por um indivíduo, foi exclusiva do quadrimestre seco do ano (Tabela 1).

Tabela 1 - Famílias de Coleoptera, com seus respectivos números de indivíduos, para cada fitofisionomia estudada e total amostrado, e considerando o quadrimestre chuvoso (fev-mai) e o seco (ago-nov), coletados com armadilha malaise no período de novembro de 2009 a outubro

de 2013, em Santa Terezinha, Paraíba. FC = Mata Ciliar, VX = Vegetação Xerófila, PC = Quadrimestre chuvoso, PS = Quadrimestre Seco

Table 1 - Coleoptera families, with their respective numbers of individuals, for each studied phytophysiognomy and total sampled, considering only the rainy and dry months, collected with malaise trap from November 2009 to October 2013, in Santa Terezinha, Paraíba state. MC = Riparian Forest, VX = Xerophilic Vegetation, PC = Rainy Period, PS = Dry Period

\begin{tabular}{lcccccccc}
\hline \multirow{2}{*}{ Família } & \multirow{2}{*}{ MC } & VX & Total & \multicolumn{3}{c}{ MC } & \multicolumn{2}{c}{ VX } \\
\cline { 5 - 8 } & & & & & PC & PS & PC & PS \\
\hline Chrysomelidae & 1300 & 699 & 1999 & 196 & 756 & 283 & 265 \\
Curculionidae & 327 & 215 & 542 & 95 & 104 & 85 & 50 \\
Tenebrionidae & 437 & 68 & 505 & 58 & 196 & 27 & 10 \\
Mordellidae & 200 & 284 & 484 & 116 & 14 & 195 & 12
\end{tabular}


Tabela 1 - Continuação ...

Table 1 - Continuation ...

\begin{tabular}{|c|c|c|c|c|c|c|c|}
\hline \multirow{2}{*}{ Família } & \multirow{2}{*}{ MC } & \multirow{2}{*}{ VX } & \multirow{2}{*}{ Total } & \multicolumn{2}{|c|}{ MC } & \multicolumn{2}{|c|}{ VX } \\
\hline & & & & PC & PS & PC & PS \\
\hline Elateridae & 352 & 81 & 433 & 89 & 168 & 46 & 4 \\
\hline Cleridae & 273 & 156 & 429 & 45 & 98 & 30 & 42 \\
\hline Coccinellidae & 313 & 63 & 376 & 91 & 52 & 27 & 16 \\
\hline Phalacridae & 183 & 71 & 254 & 66 & 28 & 43 & \\
\hline Cerambycidae & 143 & 74 & 217 & 89 & 23 & 33 & 12 \\
\hline Bostrichidae & 79 & 89 & 168 & 21 & 31 & 26 & 28 \\
\hline Ptinidae & 110 & 29 & 139 & 22 & 61 & 20 & \\
\hline Zopheridae & 72 & 65 & 137 & 32 & 23 & 32 & 16 \\
\hline Anthicidae & 122 & 2 & 124 & 108 & 6 & & \\
\hline Carabidae & 66 & 43 & 109 & 33 & 8 & 27 & 5 \\
\hline Phengodidae & 42 & 66 & 108 & 28 & 2 & 20 & 7 \\
\hline Lampyridae & 97 & 3 & 100 & 75 & & 3 & \\
\hline Buprestidae & 42 & 31 & 73 & 23 & 9 & 16 & 6 \\
\hline Staphylinidae & 60 & 9 & 69 & 45 & 12 & 5 & \\
\hline Anthribidae & 23 & 23 & 46 & 12 & 6 & 11 & 3 \\
\hline Nitidulidae & 33 & 9 & 42 & 13 & 6 & 3 & 5 \\
\hline Scarabaeidae & 10 & 23 & 33 & 5 & 3 & 22 & \\
\hline Scirtidae & 29 & 1 & 30 & 1 & 23 & & \\
\hline Aderidae & 19 & 9 & 28 & 11 & 7 & 8 & \\
\hline Oedemeridae & 11 & 16 & 27 & 2 & 2 & 8 & 1 \\
\hline Throscidae & 17 & & 17 & & 17 & & \\
\hline Dermestidae & 11 & 5 & 16 & 1 & 8 & 1 & 1 \\
\hline Scraptiidae & 8 & & 8 & 3 & 4 & & \\
\hline Leiodidae & 2 & 5 & 7 & 2 & & 1 & \\
\hline Ptilodactylidae & 7 & & 7 & 3 & & & \\
\hline Latridiidae & 5 & 1 & 6 & & 5 & & 1 \\
\hline Meloidae & 4 & 2 & 6 & 3 & 1 & 2 & \\
\hline Chelonariidae & & 5 & 5 & & & & \\
\hline Trogossitidae & 3 & 2 & 5 & 1 & 1 & 2 & \\
\hline Cantharidae & 3 & & 3 & 3 & & & \\
\hline Corylophidae & 1 & 2 & 3 & & 1 & 2 & \\
\hline Melyridae & 1 & 2 & 3 & & & & \\
\hline Silvanidae & 3 & & 3 & 1 & 1 & & \\
\hline Brentidae & 2 & & 2 & & 1 & & \\
\hline
\end{tabular}


Tabela 1 - Conclusão ...

Table 1 - Conclusion ...

\begin{tabular}{|c|c|c|c|c|c|c|c|}
\hline \multirow{2}{*}{ Família } & \multirow{2}{*}{ MC } & \multirow{2}{*}{ VX } & \multirow{2}{*}{ Total } & \multicolumn{2}{|c|}{ MC } & \multicolumn{2}{|c|}{ VX } \\
\hline & & & & PC & PS & PC & PS \\
\hline Byphilidae & 1 & & 1 & 1 & & & \\
\hline Dytiscidae & & 1 & 1 & & & 1 & \\
\hline Endomychidae & & 1 & 1 & & & & \\
\hline Histeridae & 1 & & 1 & 1 & & & \\
\hline Total (indivíduos) & 4.412 & 2.155 & 6.567 & 1.295 & 1.677 & 979 & 484 \\
\hline Total (famílias) & 39 & 34 & 42 & 34 & 32 & 28 & 18 \\
\hline
\end{tabular}

Fonte: Autores (2019)

$\mathrm{Na}$ vegetação xerófila o número médio de espécies $(\mathrm{t}=5,3018 ; \mathrm{p}<0,001)$ e de indivíduos $(t=3,6312 ; p<0,001)$ por amostra semanal coletados no período chuvoso foi estatisticamente maior do que no período seco. No entanto, não houve diferença entre as duas estações próximo à mata ciliar tanto para a riqueza de espécies $(\mathrm{t}=0,98917, \mathrm{p}=0,2281)$ quanto para a abundância de indivíduos ( $\mathrm{t}=-0,60337, \mathrm{p}=0,5474)$ (Tabela 2$)$.

Tabela 2 - Número absoluto/médio de indivíduos e de espécies e a diversidade de Shannon $\left(H^{\prime}\right)$ para os períodos chuvoso $(\mathrm{PC})$ e seco $(\mathrm{PS})$ da comunidade de Coleoptera amostrada em área de mata ciliar e vegetação xerófila, de novembro de 2009 a outubro de 2013, em Santa Terezinha, Paraíba

Table 2 - Absolute/average number of individuals and species and the index Shannon diversity for rainy season (PC) and dry (PS) periods of Coleoptera community sampled in riparian forest and dry forest area from November/2009 to October/2013, in Santa Terezinha, Paraíba state

\begin{tabular}{lccccc}
\hline \multirow{2}{*}{ Parâmetros } & \multicolumn{3}{c}{ Mata ciliar } & & \multicolumn{2}{c}{ Vegetação xerófila } \\
\cline { 2 - 3 } \cline { 5 - 6 } & PC & PS & & PC & PS \\
\hline Indivíduos & $1295 / 20,94 \mathrm{a}$ & $1677 / 25,88 \mathrm{a}$ & & $979 / 15,25 \mathrm{a}$ & $484 / 8,20 \mathrm{~b}$ \\
Riqueza & $212 / 9,18 \mathrm{a}$ & $155 / 9,01 \mathrm{a}$ & & $158 / 7,80 \mathrm{a}$ & $77 / 3,90 \mathrm{~b}$ \\
Diversidade $\left(H^{\prime}\right)$ & 4,46 & 3,91 & & 4,21 & 3,19 \\
\hline
\end{tabular}

Fonte: Autores (2019)

Em que: $\left(^{*}\right)$ Letras diferentes na linha para cada fitofisionomia não diferem estatisticamente entre si pelo teste $\mathrm{t}(\mathrm{p}<0,05)$.

Como era esperado, devido à quase ausência de folhas verdes e escassez de água e umidade no período seco, na vegetação xerófila decídua foi registrada nítida variação sazonal na abundância e riqueza de besouros com valores maiores durante o período chuvoso. Padrão semelhante tem sido reportado também em outros estudos registrando menor abundância durante o período seco na Caatinga, como para Buprestidae (IANNUZZI; MAIA; VASCONCELOS, 2006), Scarabaeidae: Scarabaeinae (HERNÁNDEZ, 2007) em Coleoptera: Sphingidae (Lepidoptera) (GUSMÃO; CREÃO-DUARTE, 2004; DUARTE JÚNIOR; SCHLINDWEIN, 2005), Collembola (FERREIRA; 
BELLINI; VASCONCELLOS, 2013) e para várias ordens de insetos, inclusive Coleoptera (VASCONCELLOS et al., 2010). No entanto, não foi observado o mesmo padrão sazonal para a abundância e riqueza na comunidade de besouros estudada próximo àmata ciliar, sendo que o número total de indivíduos coletados nessa área no quadrimestre seco foi nominalmente maior até mesmo do que o do quadrimestre chuvoso.

Não há estudos anteriores sobre comunidades de besouros em ambientes mésicos na Caatinga, para comparação, mas em estudos sobre borboletas visitantes florais realizados também na Fazenda Tamanduá concomitantemente em área na mata ciliar e em área de vegetação xerófila foi encontrado resultado similar com coleta de mais indivíduos no período seco em relação ao período chuvoso nesse ambiente, apesar de que, também a diferença no número médio por amostragem, não foi significativa (ANSELMO et al., 2014).

Das 155 espécies que ocorreram na mata ciliar durante o período seco, 64 (41,2\%) foram exclusivas dessa estação. Já, na vegetação xerófila registrou-se um número menor durante o mesmo período, das 77 espécies, 23 (29,8\%) ocorreram apenas nessa estação crítica. Destaca-se também que a maior parte das espécies $(70,1 \%)$ que ocorre durante o período seco na vegetação xerófila é de espécies que mantêm adultos ativos durante essa estação como Corinthiscus sp.2 (Cleridae) e Epitragus (Similepitragus) sp.2 (Tenebrionidae) (GUEDES; ZANELLA; GROSSI, 2019).

Ao comparar a abundância nos dois períodos avaliados em cada fitofisionomia, observa-se comportamento distinto. Na vegetação xerófila houve maior abundância durante o período chuvoso como era esperado. Porém, na mata ciliar não se observaram diferenças estatísticas entre as duas estações avaliadas (Tabela 2), embora esse comportamento tenha variado entre famílias, sendo mais evidente a coleta de mais indivíduos durante o período seco para Chrysomelidae, Cleridae, Elateridae, Ptinidae e Tenebrionidae como se observa na Tabela 1. Contudo, apenas Chrysomelidae $(\mathrm{p}<0,01)$, Cleridae $(\mathrm{p}<0,001)$ e Tenebrionidae $(\mathrm{p}<0,001)$ apresentaram diferenças no número médio de indivíduos semanal significativamente maior em relação ao período chuvoso no ambiente ciliar.

A área de vegetação xerófila estudada fica bastante seca durante o período de estresse hídrico, no qual a quase totalidade das plantas perde suas folhas e a maioria das espécies produz flores e frutos na estação chuvosa (MACHADO; BARROS; SAMPAIO, 1997). Esse fato também pode ter favorecido a área de mata ciliar a se mostrar mais rica em quantidade de espécies em comparação com o ambiente de vegetação xerófila. Por outro lado, algumas espécies de plantas são capazes de produzir flores e permanecer com folhas na estação seca (MACHADO; BARROS; SAMPAIO, 1997). Isso pode ser uma fonte importante para as populações de insetos nessa estação, contribuindo para a manutenção das espécies que conseguem permanecer nessa área seca durante esse período restritivo do ano.

De acordo com o número total de espécies amostradas em cada período, estimado por meio do método de Chao1, coletou-se o maior percentual do número estimado de espécies durante o período seco na mata ciliar (72,6\%). E o percentual de espécies mais baixo registrado foi coletado durante o período chuvoso na vegetação xerófila $(50,9 \%)$ (Tabela 3$)$. O período chuvoso para a vegetação xerófila é um momento de grande aumento na oferta de recursos tróficos o que implica na estação mais favorável do ano, apresentando um aumento na diversidade de coleópteros, para maior parte das espécies, tendo sido coletado um número alto de espécies com apenas um indivíduo o que levou a ter um número estimado alto de espécies e consequentemente o menor coletado em relação ao estimado entre as estações avaliadas.

Das 34 famílias coletadas durante o período chuvoso na mata ciliar, quatro (Byphilidae, Cantharidae, Histeridae e Ptilodactylidae) tiveram ocorrência exclusiva nos quatro meses de chuva nesta área. No entanto, Corylophidae, Latridiidae e Throscidae foram coletadas apenas nos meses secos nessa fitofiosionomia. Na vegetação xerófila foram amostradas 28 famílias durante o quadrimestre chuvoso. Destas, cinco famílias (Corylophidae, Dytiscidae, Lampyridae, Meloidae e Trogossitidae) ocorreram exclusivamente no período chuvoso e apenas Latridiidae foi exclusivamente coletada no período seco (Tabela 1). Entretanto, essas famílias apresentaram baixa ocorrência em todo levantamento. 
Tabela 3 - Número e porcentagem de espécies singleton e doubleton e seus respectivos totais, número de espécies estimadas pelo estimador Chao1, e o número de espécies de Coleoptera coletadas para as duas fitofisionomias estudadas no período chuvoso (PC) e seco (PS), no período de novembro de 2009 a outubro de 2013, em Santa Terezinha, Paraíba

Table 3 - Number and percentage of singleton and doubleton species and their respective totals, number of species estimated by Chao1 estimator, and number of Coleoptera species collected for the two phytophysiognomies studied in the rainy season (PC) and dry (PS), in the period from November 2009 to October 2013, in Santa Terezinha, Paraíba state

\begin{tabular}{lccccc}
\hline \multirow{2}{*}{ Espécies } & \multicolumn{2}{c}{ Mata ciliar } & & \multicolumn{2}{c}{ Vegetação xerófila } \\
\cline { 2 - 3 } \cline { 5 - 6 } & PC & PS & & PC & PS \\
\hline Singleton & $81(38,2 \%)$ & $53(34,2 \%)$ & & $72(45,6 \%)$ & $36(46,8 \%)$ \\
Doubleton & $31(14,6 \%)$ & $24(15,5 \%)$ & & $17(10,8 \%)$ & $10(13,0 \%)$ \\
Estimadas & 317,8 & 213,5 & & 310,5 & 141,8 \\
Coletadas & $212(66,7 \%)$ & $155(72,6 \%)$ & & $158(50,9 \%)$ & $77(54,3 \%)$ \\
\hline
\end{tabular}

Fonte: Autores (2019)

De acordo com o valor estimado de diversidade pelo índice de Shannon, considerando os distintos períodos do ano, registrou-se durante o período chuvoso na mata ciliar a maior diversidade de espécies, enquanto que a menor foi registrada na vegetação xerófila durante o período seco (Tabela 2). A diversidade beta encontrada para a comunidade de Coleoptera estudada foi de 0,42 e o índice de similaridade de Jaccard, que considera apenas a composição de espécies, entre as áreas foi estimado em 0,41 . O que pode ser considerada uma similaridade intermediária na composição entre as áreas, podendo haver bastante substituição de espécies entre as amostras. Observa-se que mesmo sendo áreas próximas espacialmente, o fato da manutenção de uma melhor condição microclimática ao longo do ano na área ciliar favorecendo para que as plantas permaneçam verdes durante o período de estiagem contribui, provavelmente, para a formação de condições ambientais locais distintas o que leva à existência de uma composição de similaridade intermediária de coleópteros entre as áreas avaliadas.

Foram registradas correlações entre as variáveis temperatura ( $r s=-0,157 ; \mathrm{p}<0,01)$ e umidade $(\mathrm{rs}=0,215 ; \mathrm{p}<0,01)$ e a abundância de indivíduos na mata ciliar. Por outro lado, para a vegetação xerófila constatou-se correlação entre as variáveis precipitação ( $r s=0,299 ; p<0,001)$ e umidade $(\mathrm{rs}=0,259, \mathrm{p}<0,001)$ e a abundância de indivíduos. Esses resultados ratificam o padrão observado na variação registrada na abundância da comunidade de besouros, e evidencia a importância da precipitação como um dos fatores diferenciais para o padrão sazonal da fauna de besouros na vegetação xerófila, fato esse, não observado para a mata ciliar. Para a fauna de Chrysomelidae, Linzmeier e Ribeiro-Costa (2013), encontraram correlação apenas com as variáveis fotoperíodo, temperatura e umidade relativa em diferentes localidades no Paraná, ainda assim as duas últimas variaram com a localidade.

A análise de partição da diversidade beta temporal (decomposição do beta representando a variação temporal na composição das espécies) indicou que a escala que melhor explicou a diversidade temporal de Coleoptera foi o turnover em ambas as fitofisionomias. Com isso, a substituição de espécies foi o componente mais importante, sendo o que mais contribuiu para a diversidade beta e representou $83 \%\left(\beta_{\mathrm{SOR}}=0,51\right)$, enquanto o aninhamento $\left(\beta_{\mathrm{SNE}}=0,10\right)$ representou apenas $17 \%$ na mata ciliar. Comportamento similar foi registrado para a vegetação xerófila no qual a substituição de espécies foi responsável por $66 \%\left(\beta_{\mathrm{SOR}}=0,41\right)$ e o aninhamento por $34 \%\left(\beta_{\mathrm{SOR}}\right.$ $=0,21$. .

Observou-se, assim, uma elevada con tribuição do turnover para a composição da diversidade 
beta da comunidade em ambos os ambientes, ou seja, o mecanismo que mais contribui para o padrão da biodiversidade é a substituição de espécies, ou ainda, a dissimilaridade existente entre os ambientes, deriva principalmente desse padrão ecológico. Os valores da diversidade beta podem ser resultado de dois processos extremamente diferentes: devido ao turnover, ou substituição de espécies temporal entre os ambientes, ou devido ao aninhamento, quando as espécies não são substituídas, mas perdidas de um local para outro (BASELGA, 2010). Resultados similares foram encontrados para a comunidade de formigas em pesquisa realizada na mesma propriedade de estudo por Silva et al. (2017b), o que pode ser um indício de padrão para as comunidades de insetos na região, embora as formigas apresentem hábitos sociais.

Os resultados da PERMANOVA para a coleóptero fauna coletada nas duas fitofisionomias apontam que há diferenças na estrutura da comunidade entre as áreas estudadas $\left(R^{2}=0,01822\right.$, $\mathrm{p}<0,001)$, e também diferenças sazonais $\left(\mathrm{R}^{2}=0,02147, \mathrm{p}<0,001\right)$. Contudo, não foi encontrada diferença na composição dos coleópteros entre as áreas $(\mathrm{F}=0,7414 ; \mathrm{p}=0,391)$, mas registrou-se diferença significativa sazonal para a composição $(\mathrm{F}=3,9165 ; \mathrm{p}=0,007)$. Por meio da análise de PCoA ficou evidente a formação de dois agrupamentos com grande sobreposição entre eles e que, com isso, as diferenças espaciais e sazonais detectadas na PERMANOVA advêm das variações das abundâncias de indivíduos das espécies de coleópteros entre os ambientes estudados (Figura1).

Figura 1 - Diagrama de ordenação de PCoA para a comunidade de Coleoptera, amostrada em duas fitofisionomias de Caatinga, entre novembro de 2009 a outubro de 2013, Santa Terezinha, Paraíba. FC = Mata Ciliar, VX = Vegetação Xerófila

Figure 1 - Principal coordinate analysis (PCoA) ordering diagram for the Coleoptera community, sampled in two Caatinga phytophysiognomies, between November/2009 and October/2013, Santa Terezinha, Paraíba state. FC = Riparian Forest, VX = Xerophilous Vegetation

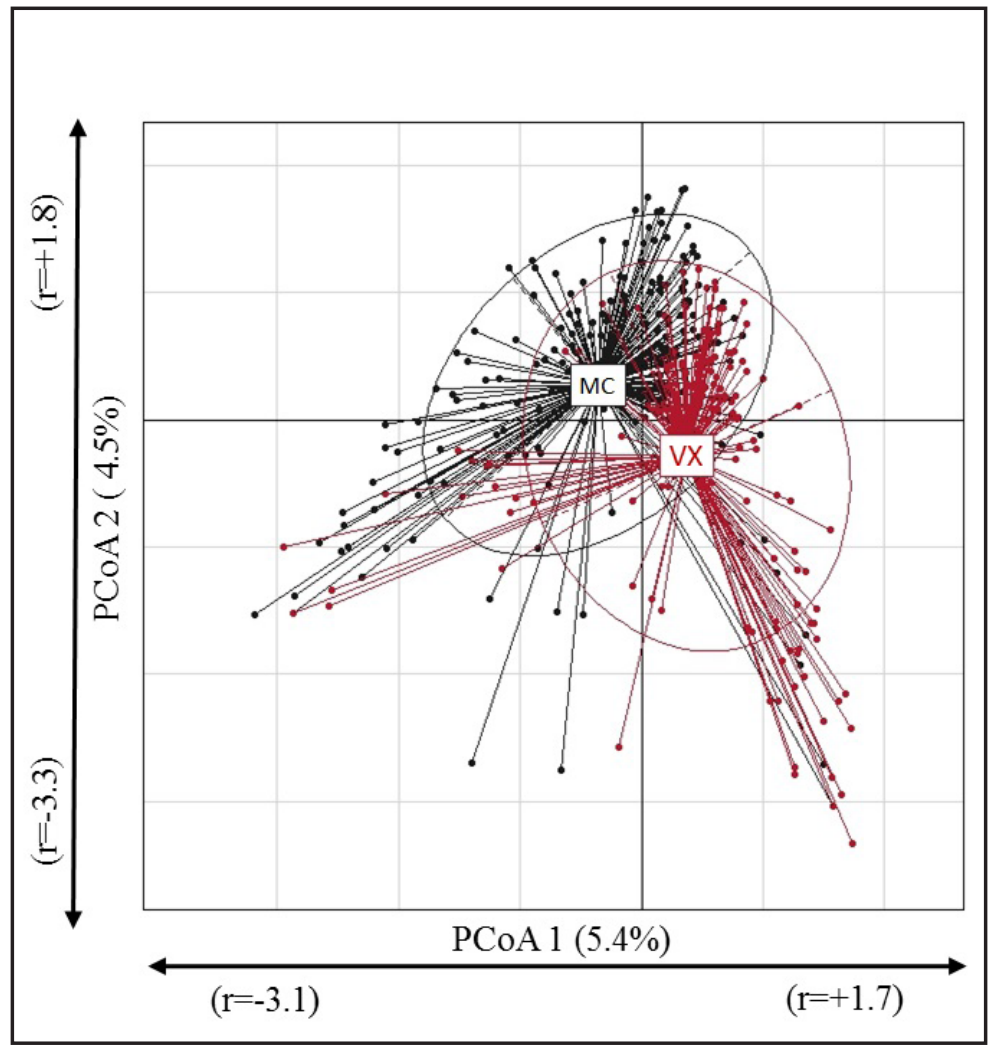

Fonte: Autores (2019) 
Os fatores abióticos influenciam na estrutura das comunidades, e as variações climáticas podem definir a distribuição, desenvolvimento, comportamento e de forma indireta na alimentação dos organismos, bem como na sazonalidade da entomofauna local (SILVEIRA NETO et al.,1976). Segundo Wolda (1988), a abundância de insetos pode ser alterada ao longo do tempo por várias razões, incluindo mudanças macro e microclimáticas e variação na disponibilidade de recursos alimentares. Ganho e Marinoni (2003) apontam como provável fator a disponibilidade trófica do ambiente que tende a favorecer uma ou outra família para explicar a diferença na representação das famílias ao longo do tempo e espaço.

É provável que, apesar de se tratar de áreas relativamente próximas, o efeito da manutenção da umidade do solo na mata ciliar e a vegetação sempre verde durante todo o ano (PRADO, 2003) propicie durante a estação seca um ambiente com condições mais favoráveis em comparação à área de vegetação xerófila predominante, permitindo ser um refúgio para a manutenção de populações de espécies com indivíduos adultos ativos durante esse período desfavorável. Essa interpretação é corroborada pela maior riqueza, abundância e diversidade de besouros nesse ambiente ciliar em relação à vegetação xerófila.

\section{Conclusões}

A ordem Coleoptera apresenta movimentação de indivíduos advindos da área com vegetação xerófila para a área ciliar durante o período de estresse hídrico. Apesar da ação antrópica, a mata ciliar atua tanto na manutenção de maior número de indivíduos de Coleoptera por um período mais prolongado ao longo do ano, quanto servindo de refúgio abrigando indivíduos de populações que migram de áreas secas do seu entorno durante a estação seca.

Além disso, os resultados encontrados neste estudo corroboram evidências prévias do caráter fortemente sazonal da comunidade de coleópteros em vegetação xerófila de Caatinga no Semiárido do Nordeste brasileiro, reduzindo significativamente no período seco a abundância de indivíduos. Fato esse não observado para a mata ciliar, na qual não foi observada diferença entre as duas estações analisadas, evidenciando, assim, a importância da presença das matas ciliares na Caatinga, sendo essenciais na manutenção e conservação de coleópteros, especialmente durante o período de estiagem, nos ecossistemas de Caatinga.

\section{Agradecimentos}

Ao Sr. Pierre Landolt proprietário da Fazenda Tamanduá pela permissão para as coletas em sua propriedade, ao CNPq, por ter financiado o projeto de pesquisa "Diversidade, Ecologia e Conservação de Himenópteros na Região Semiárido do Nordeste do Brasil, com Ênfase nas Abelhas", em nome de FCVZ, o que permitiu a realização das amostragens, ao Sr. Ayr de Moura Bello (Rio de Janeiro-RJ), a Prof ${ }^{a}$. Dra. Lúcia Massuti Almeida (Universidade Federal do Paraná, Curitiba-PR) e ao Dr. Angelico Fortunato Asenjo Flores (Universidade Federal do Mato Grosso, Cuiabá-MT), pelas identificações dos besouros.

\section{Referências}

ANDERSON, M. J.A new method for non-parametric multivariate analysis of variance. Austral Ecology, Sidney, v. 26, p. 32-46, 2001.

ANSELMO, F. A. etal. Abundância, riqueza de espécies e sazonalidade de borboletas (Lepidoptera: Hesperioidea e Papilionoidea) visitantes florais em área de Caatinga e floresta ciliar no Semiárido 
paraibano. Journal of Biology \& Pharmacy and Agricultural Management, Campina Grande, v. 10, n. 1, p. 97-110, 2014.

BASELGA, A. Partitioning the turnover and nestedness components of beta diversity. Global Ecology and Biogeography, Arizona, v. 19, p. 134-143, 2010.

BASELGA, A.; ORME, C. D. L. Betapart: an R package for the study of beta diversity. Methods in Ecology and Evolution, London, v. 3, p. 808-812, 2012.

BOUCHARD, P. et al. Biodiversidade of Coleoptera. In: FOOTTIT, R. G.; ADLER, P. H. (ed.). Insect Biodiversity: science and society. 2nd ed., Hoboken: John Wiley \& Sons, 2017. p. 337-417.

CASARI, S. A.; IDE, S. Coleoptera Linnaeus, 1758. In: RAFAEL, J. A. et al. Insetos do Brasil: diversidade e taxonomia. Ribeirão Preto: Holos, 2012. p. 454-535.

COLWELL, R. K. EstimateS: statistical estimation of species richness and shared species from samples. User's guide. [S. l.: s. n.], 2005. Disponível em: http://viceroy.eeb.uconn.edu/EstimateS. Acesso em: 03 mar. 2017.

DRAY, S. et al. Ade4: analysis of ecological data: exploratory and Euclidean methods in environmental sciences. [S. l.: s. n.], 2018. Disponível em: https://cran.r-project.org/web/packages/ ade4/index.html. Acesso em: 20 mar. 2018.

DUARTE JÚNIOR, J. A.; SCHLINDWEIN, C. The highly seasonal hawkmoth fauna (Lepidoptera: Sphingidae) of the Caatinga of Northeast Brazil: a case study in the state of Rio Grande do Norte. Journal of the Lepidopterists' Society, San Francisco, v. 59, n. 4, p. 212-218, 2005.

FERREIRA, A. S.; BELLINI, B. C.; VASCONCELLOS, A. Temporal variations of Collembola (Arthropoda: Hexapoda) in the semiarid Caatinga in northeastern Brazil. Revista Brasileira de Zoologia, Curitiba, v. 30, n. 6, p. 639-644, 2013.

GANHO, N. G.; MARINONI, R. C. Fauna de Coleoptera no Parque Estadual de Vila Velha, Ponta Grossa, Paraná, Brasil. Abundância e riqueza das famílias capturadas através de armadilhas malaise. Revista Brasileira de Zoologia, Curitiba, v. 20, n. 4, p. 727-236, 2003.

GUEDES, R. S.; ZANELLA, F. C. V.; GROSSI, P. C. Composição, riqueza de espécies de uma comunidade de Coleoptera (Insecta) na Caatinga. Iheringia Série Zoologia, Porto Alegre, n. 109, p. e2019012, 2019.

GULLAN, P. J.; CRANSTON P. S. Os insetos: um resumo de entomologia. São Paulo: Roca, 2012. $479 \mathrm{p}$.

GUSMÃO, M. A. B.; CREÃO-DUARTE, J. A. Diversidade e análise faunística de Sphingidae (Lepidoptera) em área de brejo e Caatinga no Estado da Paraíba, Brasil. Revista Brasileira de Zoologia, Curitiba, v. 21, n. 3, p. 491-498, 2004.

HERNÁNDEZ, M. I. M. Besouros escarabeíneos (Coleoptera: Scarabaeidae) da caatinga paraibana, Brasil. Oecologia Brasiliensis, Rio de Janeiro, v. 11, n. 3, p. 356-364, 2007.

IANNUZZI, L.; MAIA, A. C. D.; VASCONCELOS, S. D. Ocorrência e sazonalidade de coleópteros buprestídeos em uma região de caatinga nordestina. Biociências, Porto Alegre, v. 14, n. 2, p. 174$179,2006$.

LINZMEIER, A. M.; RIBEIRO-COSTA, C. S. Seasonal pattern of Chrysomelidae (Coleoptera) in the state of Paraná, southern Brazil. Biota Neotropica, Campinas, v. 13, n. 1, p. 153-162, 2013.

MACHADO, I. C. S.; BARROS, L. M.; SAMPAIO, E. V. S. B.Phenologyof Caatinga Species at Serra Talhada, PE, Northeastern Brazil. Biotropica, São Paulo, v. 29, n. 1, p. 57-68,1997.

MAGURRAN, A. E. Medindo a diversidade biológica. Curitiba: UFPR, 2011. 261 p.

OKSANEN, J. et al. Vegan: Community Ecology Package. R package version 2. [S. l.: s. n.], 2013.

Ci. Fl., Santa Maria, v. 30, n. 4, p. 995-1007, out./dez. 2020 
Disponível em: http://vegan.r-forge.r-project.org/. Acesso em: 20 mar. 2018.

PENNINGTON, R. T. et al. Historical climate change and speciation: neotropical seasonally dry forest plants show patterns of both Tertiary and Quaternary diversification. Philosophical Transactions of the Royal Society B Biological Sciences, London, v. 359, n. 1443, p. 515-537, 2004.

PINHEIRO, F. et al. Seasonal pattern of insect abundance in the Brazilian Cerrado. Austral Ecology, Armidale, v. 27, n. 2, p. 132-136, 2002.

PRADO, D. As caatingas da América do Sul. In: LEAL, I. R.; TABARELLI, M.; SILVA J. M. C. (ed.). Ecologia e conservação da Caatinga. Recife: Editora Universitária, 2003. p. 3-73.

R DEVELOPENT CORE TEAM. 2016. R: a language and environment for statistical computing. Vienna: R Foundation for Statistical Computing, 2016. Disponível em: http://www.R-project.org. Acesso em: 02 dez. 2016.

SILVA, J. O.; NEVES, F. S. Insect herbivores associated with an evergreen tree Goniorrhachis marginata Taub. (Leguminosae: Caesalpinioideae) in a tropical dry forest. Brazilian Journal of Biology, São Carlos, v. 74, n. 3, p. 623-631, 2014.

SILVA J. M. C. et al. The Caatinga: understanding the challenges. In: SILVA, J. M. C.; LEAL, I. R.; TABARELLI, M. (ed.). Caatinga: the largest tropical dry forest region in South America. [S. l.]: Springer, 2017a. p. 1-19.

SILVA, L. F. et al. Ant diversity in Brazilian tropical dry forests across multiple vegetation domains. Environmental Research Letters, Berkeley, v. 12, n. 3, p. 1-11, 2017b.

SILVEIRA NETO, S.et al. Manual de ecologia dos insetos. Piracicaba: Editora Agronômica Ceres, 1976. 419 p.

VASCONCELLOS, A. et al. Seasonality of insects in the semi-arid Caatinga of the northeastern Brasil. Revista Brasileira de Entomologia, São Paulo, v. 54, n. 3 p. 471-476, 2010.

VELLOSO, A. L.; SAMPAIO, E. V. S. B.; PAREYN, F. G. C. Ecorregiões propostas para o bioma caatinga. Recife, Associação Plantas do Nordeste, Instituto de Conservação Ambiental, The Nature Conservancy do Brasil. 2002. 75 p.

WOLDA, H. Insect seasonality: why? Annual Review of Ecology and Systematics, Palo Alto, v. 19, p. 1-18,1988.

ZANELLA, F. C. V. Abelhas da Estação Ecológica do Seridó (Serra Negra do Norte, RN): aportes ao conhecimento da diversidade e abundância e distribuição espacial das espécies na caatinga. In: MELO, G. A. R.; SANTOS, I. A. (ed.). Apoidea Neotropica. Homenagem aos 90 anos de Jesus Santiago Moure. Criciúma: UNESC, 2003. p. 231-240. 